\title{
The Arabic/French codic alternation in the explanations of teachers of French in Morocco
}

\author{
Mariam SAHRAOUI * and Abdelhamid IBN EL FAROUK \\ Hassan II University, FLSH Mohammedia Interdisciplinarity Laboratory of Humanities and Social Sciences.
}

Global Journal of Engineering and Technology Advances, 2022, 10(01), 100-106

Publication history: Received on 12 December 2021; revised on 22 January 2022; accepted on 24 January 2022

Article DOI: https://doi.org/10.30574/gjeta.2022.10.1.0022

\begin{abstract}
The analysis focus on the use of Arabic and French by the teacher in a foreign language class in a Moroccan context. This activity, codic alternation or code-switching, is analyzed through an observation of three different teachers while keeping the same level (3rd year of college secondary). All three used code switching in their speech in class, although this manifestation differed from teacher to teacher.

It is however imperative to underline that this research work is not intended to provide solutions for the use of code alternation in class, far from it, it is simply a qualitative study allowing understanding of this sociolinguistic phenomenon and the reflection on its use in a didactic situation.
\end{abstract}

Keywords: Code alternation; Sociolinguistic phenomenon; Observation; Analysis; Determination of the problem

\section{Introduction}

The present study comes at the crossroads of two linguistic theories, namely sociolinguistics, more particularly the phenomenon of language contact, and the didactics of French. Since the eighties, J. J. GUMPERZ uses interactional sociolinguistics to study the contact of languages in different situations. The codic alternation, which is the object of our study, is one of the manifestations of this contact, it is even one of the most common strategies of bilingualism. In Morocco, the sociolinguistic landscape is very diverse. This is governed by well-defined historical, socio-political and cultural rules. As a result, codic alternation has become a very common manifestation, whether in a social, family, administrative or educational setting. The latter, which is the main object of this research, constitutes a problem to be solved.

In this sense, there have been several researches that have addressed this phenomenon. However, they were only interested in codic alternation from the learner's side. The present study focuses on another actor of this phenomenon, namely the teacher. Indeed, the teaching of a L2 by L1 interlocutors can be quite tricky. The academic inspectors have decided that these courses must be given only in the language being taught. On the other hand, and through the observation conducted in a French class in a public college in 2017 we noticed a great manifestation of this alternation in the teacher.

This research aims to understand this sociolinguistic phenomenon in a didactic situation well. It tries to answer the following question: How does the Arabic/French codic alternation manifest itself in a foreign language course in the teacher?

\footnotetext{
${ }^{*}$ Corresponding author: Mariam SAHRAOUI

Hassan II University, FLSH Mohammedia Interdisciplinarity Laboratory of Humanities and Social Sciences. 


\section{Theoretical framework}

\subsection{The linguistic situation in Morocco}

In its history, Morocco has known a diversity and multiplicity at the level of the people who live there, several cultures, customs and obviously languages have left their traces. This situation has resulted in the presence of several languages that cohabit with each other, each with a different status.

This part focuses on the six main languages used in Morocco, namely

- Dialectal Arabic

- Amazigh

- Standard Arabic

- French

- English

- Spanish

We have, first of all, Dialectal Arabic (DA) and Amazigh. These two languages are commonly used in the family environment and can be considered as first languages of socialization in Morocco.

Nevertheless, it should be noted that the nuance (question of importance and use) between the two is very ambiguous: There are Moroccans who speak Amazigh, others who use (DA), this is only explained by the geographical area where they live or their origins.

Dialectal Arabic is not included in educational programs or as a language of professionalization, it is a dialect that is used to communicate in different contexts. On the other hand, Amazigh, which was mainly a language reserved for orality, exploited with its three classes, Amazigh, Tarifit and Tachelhit, has seen a fairly significant integration at school level in recent years, mainly with the constitution of 2011 where it is listed as an official language of the country with Arabic.

Standard Arabic (SA), is - according to the 2011 constitution - the official language of the country. This language is not present in the family discourse, nor in the social discourse of Moroccans. It appeared with "the first Muslim troops of Oqba Ben Nafi" and then spread throughout the country. This language is considered, by some sociolinguists, as a "sacralized language" [1], appellation coming from the fact that it is rather linked to religion, i.e. the context in which it appeared: in the Koran, the words of the Hadith... However, Standard Arabic, or Modern Standard Arabic is very much prized and exploited in the field of communication (Medias), the press and literature. It is taught in Moroccan schools from the kindergarten level, and therefore from the moment one enters school until the baccalaureate.

As for foreign languages, their presence is mainly limited to French, English and Spanish for a rather small community.

With colonization, the status of the French language took root to become the official language of the country, present in all fields. After Morocco's independence in 1956, French took on an "ambiguous" status insofar as it was used in all fields (educational, administrative, and social) but without any precise and exact designation.

The second foreign language in Morocco, which is English, has a rather low and restricted status, but it is growing day by day as a step towards globalization. The educational environment is mostly - if not the only - area where this language is present:

- Taught from the third year of secondary school in the public sector.

- Present from the first year of primary school in the private sector.

- Being a language of instruction in the few foreign American schools.

The northern regions of Morocco still have a trace of Spanish, a language that, like French, was imposed following the colonization of the country. Nevertheless, and unlike French, it has not kept a formal status within the country, only a small community in the north uses it in daily oral communication. 


\subsection{Defining concepts}

For centuries, people - everywhere in the world - have been moving, cultures have been colliding, and languages have been meeting. It is mainly from this fact that the codic alternation was born, it is one of the results of the contact between languages.

According to J.J GUMPERZ, sociolinguist and founder of interactional sociolinguistics, code-switching is "like the juxtaposition within the same verbal exchange of passages where the discourse belongs to two different grammatical systems or subsystems". [6]

This is a phenomenon that occurs when a bilingual speaker uses two or more codes in the same utterance in different situations. Speaker y may use an L2 to respond to what speaker x has said in an L1.

This alternation of languages is common in different contexts, be it in a social, family or work setting... And these speakers do not always pay attention to the codes they use in their conversation.

Sociolinguists who have been interested in code-switching have identified a number of forms and types. In our research, we rely on two main models, that of GUMPERZ (1989) [6] and that of POPLACK (1980) [8].

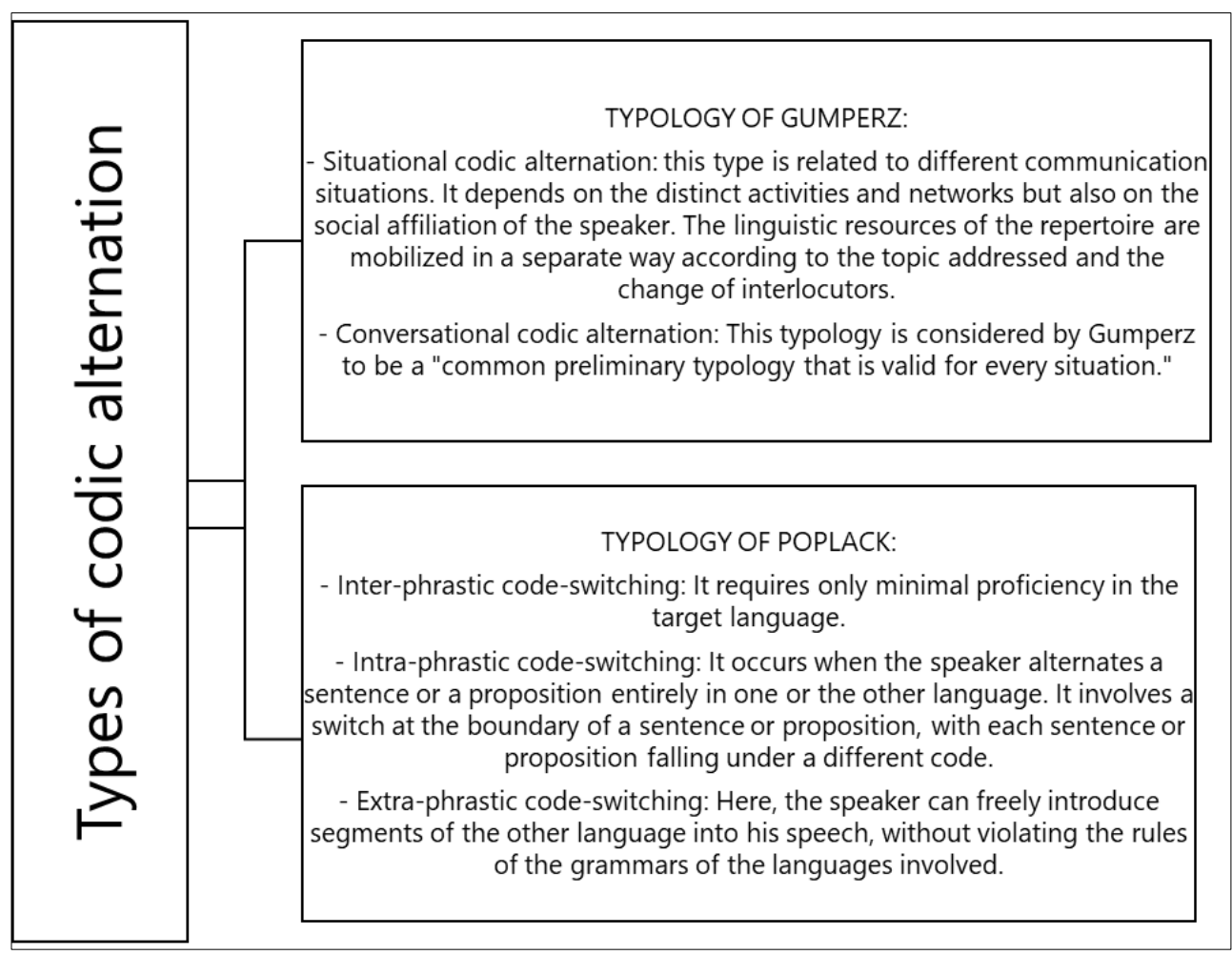

Figure 1 Types of codic alternation

GUMPERZ (1972) and POPLACK (1980) [8], the figure represents the types of codic alternation according to the two authors. The first distinguishes two types of codic alternation: situational and conversational. While the second present's three types of codic alternation: inter-phrastic, intra-phrastic and extra-phrastic codic alternation.

The functions of codic alternation vary according to the field of application, they explain how and for what purpose codic alternation is used in a conversation. In this section, we present the six functions defined by GUMPERZ (1989):

\subsubsection{The quotation}

Used frequently, it refers in a different language (L2) from the source language (L1). This allows the speaker who uses it to detach and distance himself from the content of this quotation. 


\subsubsection{Naming a speaker}

This code-switching is used to draw attention to and address a third person not involved in the initial conversation. This confers a role to the speaker using this code-switching by directing the debate and distributing the word. Moreover, it allows the exclusion of other interlocutors and to establish a more specific contact with this third person. Codeswitching ensures a cooperative relationship with the interlocutor by creating a feeling of trust, which can favourably determine the continuation of a conversation.

\subsubsection{The interjection}

Is used to show the speaker's feeling. Pronounced in any language, it is used to mark an interjection. It is the association of a personal feeling with the language of choice. The interjection can have different meanings depending on the language used.

\subsubsection{Reiteration}

The fact of repeating an expression or a notion in a different language represents the function of repetition in the alternation of codes. Serving to emphasize or clarify a message, repetition is a stylistic representation of code-switching.

\subsubsection{The modeling of a message}

This function according to GUMPERZ, "consists in modeling constructions such as sentence and complement of the verb, or predicates following a copula". It expresses the speaker's position on the relative importance of the information he transmits in his message.

\subsubsection{Personalization versus objectification}

this function uses the fact that some language in a speaker's register can be used to express objective or subjective facts in order to distance itself from the content or be authoritative. [7]

It is necessary to make the difference between codic alternation and linguistic borrowing. They are both phenomena resulting from the contact of languages, nevertheless, there is a distinction - not very obvious - between the two.

Linguistic borrowing occurs mainly in the situation where several languages are used in a geographical area. In the Dictionary of Linguistics, it is defined as "linguistic borrowing occurs when a language 'A' uses and ends up integrating a linguistic unit or trait that previously existed in a language ' $\mathrm{B}$ ' and that ' $\mathrm{A}$ ' did not possess; the borrowed unit or traits are themselves called borrowings." [5]

Codic alternation and linguistic borrowing are both phenomena resulting from language contact, nevertheless, there is a distinction - not very obvious - between the two. While code-switching is based on the meaningful juxtaposition of what, with or without awareness, speakers must treat as strings formed according to the internal rules of two distinct grammatical systems, borrowing flows into the host language and becomes part of it. It is the borrowing of a word or expression from a language $\mathrm{B}$, without translating it, and adapting it to a language 1 , which is the language of speaker $\mathrm{X}$.

\subsection{Codic alternation in a didactic context}

In this research, the aim is to work on the phenomenon of codic alternation in a didactic context, and more particularly in a French class. The codic alternation comes here as a language practice through which the teacher can resort to the first language of socialization to explain the target language, since it is not a simple communication situation, but a whole interaction which implies rules of a didactic but also pedagogical nature.

This practice has been rejected for a long time in didactics, and this because of several approaches that have shaped didactics in the 20th century.

With the failure of the traditional method, also called the grammar-translation method, and whose concept is to put forward "the reading, the comprehension and the translation of literary texts (themes/versions) where the learner applies the rules of grammar which were taught to him in an explicit way in his native language. The source language remains the language of instruction and has a primary function" (La méthodologie traditionnelle, n.d.). The meaning of words was learned through their translation into the mother tongue.

This practice therefore had a limited reception, since it did not take into account oral activity, so learners were unable to formulate a sentence in the target language, and rarely to produce a written essay. 
COSTE cites four arguments in this sense (the reasons for rejection): "reference to natural acquisition", "good use of limited time", "maximum learner demand" and "cognitive separation between L1 and L2" [4]

By the first argument, COSTE means that the appropriation of the target language can be done in "natural" conditions, with communication and interaction processes. The second argument refers to time management, since the course is conducted in a reduced time, it is preferable and recommended to make the most of it for the target language in class and to solicit the learner, considered as a subject of knowledge.

For the cognitive separation between L1 and L2, COSTE thinks that the non-recourse to the mother tongue will avoid the learner to fall into interferences... etc.

CAUSA (1996) [3] emphasizes the teacher as an important pole in didactics. She explains that the codic alternation employed by the teacher is a natural practice in accordance with any language contact communication situation. She argues that the use of the mother tongue in the acquisition of a target language is not, as has often been thought, harmful or negative in the learning process.

Through an observation of a set of collected data, she finds that in some passages, the use of codic alternation by the teacher is frequent, although too different degrees.

CAUSA (2002) [2] invites, through her work, to think of codic alternation not only as a didactic teaching/learning strategy, but also as a communicative strategy encouraging interaction between the teacher and the learner.

\section{Codic alternation in the teacher's discourse}

\subsection{Observation}

In order to analyze the manifestations of the phenomenon of codic alternation in a French class, it is imperative to report on the different situations in which the teacher resorts to codic alternation in order to evaluate its efficiency, and for this, we opted for the observation of three different classes, with three different teachers keeping the same level (3rd year of secondary school). All three employed codic alternation in their classroom discourse, although this manifestation differed from teacher to teacher:

- Teacher 1 uses dialectal Arabic in classroom discourse in communicative situations where the utterance produced is not related to the subject matter of the course, e.g. asking a student to change seats, or to be quiet, or to reprimand him...etc. It prohibits learners from using Arabic in class.

- Teacher 2 uses dialectal Arabic during French class to explain some difficult words that learners cannot understand. However, learners are strictly forbidden to use dialectal Arabic for any reason. For example, in one of the situations observed, a student asked the teacher if she could change places to work on an exercise with her classmate, the entire statement she produced was in dialectal Arabic, so the teacher asks her to rephrase the sentence in French, and, faced with the student's inability, she denies her request "Since you can't say it in French, then it's no, stay in your seat." Thus, the lesson still takes place in strict normalities, with no interaction between teacher and learner, except for a few ready-made, short answers within the framework of the activity being taught.

- $\quad$ Teacher 3 uses dialectal Arabic to interact with the learner

He does not forbid learners to use it during the session, but tries to limit it as much as possible. During the lesson and during the explanations given, French is the only language present in his speech.

Two main findings can be drawn from this approach:

- The teachers in question are aware of the alternation between the codes they use, this is generally manifested as a last choice which, for them, allows the clear transmission of the message.

- As for the learners, as soon as they are stopped in their tracks, they stop all attempts at communication, only 4 or 5 learners out of $38 \sim 48$ (approximate number of classes observed) speak up and seem to be able to formulate sentences in the language of instruction/teaching (French). 


\section{Discussion}

If we condense the results of the data collected in our observation and interview, we can draw the mode of use:

The teacher uses codic alternation to:

- Organize the work in class through indications

- Give moral lessons

- Explain difficult words

- Comment on the discipline and attitude of the students

- Sanction students

The didactic reasons for the use of Arabic in French lessons can be summarized as the explanation of difficult words, as teachers try to take into account the recommendations of the inspectors. However, there are other reasons, which we can describe as psychological, that explain the use of codic alternation by teachers. These reasons are manifested globally in all aspects that are not related to the course (imposing silence, sanctioning students, etc.)

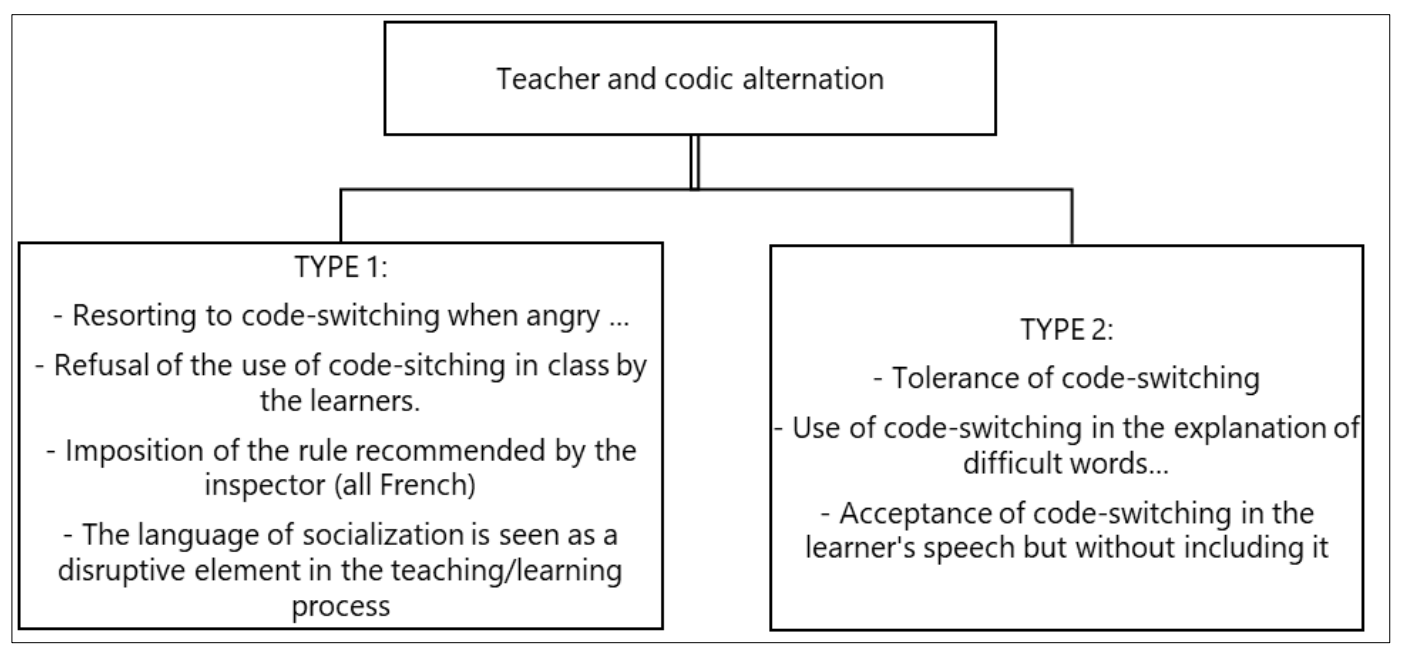

Figure 2 Types of recourse to codic alternation in the teacher's discourse

Following the observant

ion of three teachers, we can propose two types of codic alternation in the teacher's discourse.

The first category of teachers acts according to the pedagogical instructions designated by the academic inspectors. They see codic alternation as a necessary evil in the teaching-learning process and avoid using it in class as much as possible.

In this sense, Georges LUDI, professor at the Institute of French and Francophone Studies at the University of Basel, says: "such an attitude results from a breach of the didactic contract on the part of the teacher, who subordinates his or her main task, which is to enable students to learn by communicating, to other priorities.

The second category of teachers is more tolerant with code-switching, they explain it by the incompetence and low level of the students who sometimes lack the words and means to express themselves in the target language. Therefore, instead of punishing them and cutting them off, they call them to order and try to use a strategy to solve the problem.

\section{Conclusion}

Within the framework of this study, our aim is to show the manifestations of codic alternation -an inescapable fact in a multilingual country- in a didactic context. From the problematic put forward in the introduction, we have tried, through observation, to give an account of this sociolinguistic fact in the language classroom, to identify its types and functions. 
In the first part, we have tried to make the tour and to bring a clear and sharp image on what it is the codic alternation, its foundations, its types, functions and forms of use. The second part, which is an analysis and interpretation of what was observed during the observation of the classes, allows for a better understanding and vision of codic alternation in the didactic context: First of all, it must be noted that the presence of the source language in a target language course is a reality. Official pedagogical texts and inspectors may well recommend avoiding it, but practice reveals something else: Code-switching is always present, in one form or another. In some cases, it makes it easier for the teacher to understand a few words to the learners, and avoids blocking them when they speak. However, it should be noted that this recourse is made in a spontaneous way in class, a way that is not thought out either didactically or pedagogically speaking.

\section{Compliance with ethical standards}

\section{Acknowledgments}

We would like to thank all the people who gave us the information necessary to write this article.

\section{Disclosure of conflict of interest}

Working as a team can have its worries. However, we worked together with great sympathy.

\section{References}

[1] Benzakour F all. French in Morocco: lexicon AND language contacts, French Language News, Bruxelles: Duculot Editions; 2000.

[2] Causa M. Codic alternation in the teaching of a foreign language. - Bilingual teaching strategies and transmission of foreign language knowledge, Bruxelles: European University Publications; 2002.

[3] Causa M. «Codic alternation in the teacher's discourse», Cediscor Notebooks. 1996; n4: 111-129.

[4] Coste D. « Didactic Alternations», Studies in Applied Linguistics. 1997; n¹08: 393 - 394.

[5] Dubois J. \& all. Dictionary of linguistics and language sciences, Paris: Larousse Editions; 2012.

[6] Gumperz, J. Sociolinguistique interactionnelle. An interpretative approach, Saint-Denis de la Réunion, Paris : La Réunion University, L'Harmattan Editions ; 1989.

[7] Horsman, S-Gh. What is the function of codic alternation in verbal exchange ? Master's thesis, Stockholm University; 2015.

[8] Poplack S. «Sometimes I'll start a conversation in Spanish y termino en espanol: toward a typology of codeswitching », Linguistics. 1980; n¹8: 581-616. 